\title{
Increase the Reliability of Operation of Protection DC traction substation
}

\author{
Leonid L. Alekseev ${ }^{1}$, Anton A. Kolesnikov, ${ }^{2, *}$, Boris V. Papkov ${ }^{1}$, and Sergey Osokin ${ }^{3}$ \\ ${ }^{1}$ Nizhny Novgorod State University of Engineering and Economics, 606340, Knyaginino, Russian Federation \\ ${ }^{2}$ Altair Ltd, 603163, Nizhny Novgorod, Russian Federation \\ ${ }^{3}$ NSTU n.a. R.E. Alekseev, Nizhniy Novgorod, Russian Federation
}

\begin{abstract}
For protection of direct current (DC) traction substation is proposed to use centralized differential protection. Estimation of reliability indicators is carried out on the basis of the method of Markov chains. The obtained results allow to make a conclusion about the prospects of implementing this protection.
\end{abstract}

\section{Introduction}

To protect special electrical installations of DC traction substation, current protections of transformers and rectifiers [1], special DC protections [2], and ground protections are used. These technical solutions are characterized by low selectivity and outdated element base. The purpose of research is the development of highly reliable centralized differential protection (CDP) for DC traction substation.

\section{Realization of proposed protection}

The CDP proposed by the authors is based on the differential principle in combination with the double entry method [3, 4]. To describe the principle of protection, consider the fragment of the $\mathrm{DC}$ traction substation shown in fig. 1.

For the scheme (fig. 1) construct a unidirectional graph (fig. 2a) with vertices and arcs, where vertices V1 to V13 of the graph are protected items, and arcs e1 e14, respectively, the branches of current transformers (CT), current sensors (CS) and circuit breakers. The arcs that characterize the branch of the CT, CS and switches, display the facts switching and have a weight that represents information about the magnitude flowing in the branch current obtained by measurement using the appropriate CT and CS.

The next step is the definition of range of protection based on the topology of scheme with the position of the isolators. As a result, possible transition to a new form of the graph (fig. 2b) by deleting the arcs e3-e6, e9, e10 and merge the vertices V6-8 (V6*) and V9-12 (V7*).

For determining the location of fault, protection compares the currents on differential principle for particular regions and detects potentially damaged item. For all graph vertices with degree $>1$ compile equations.

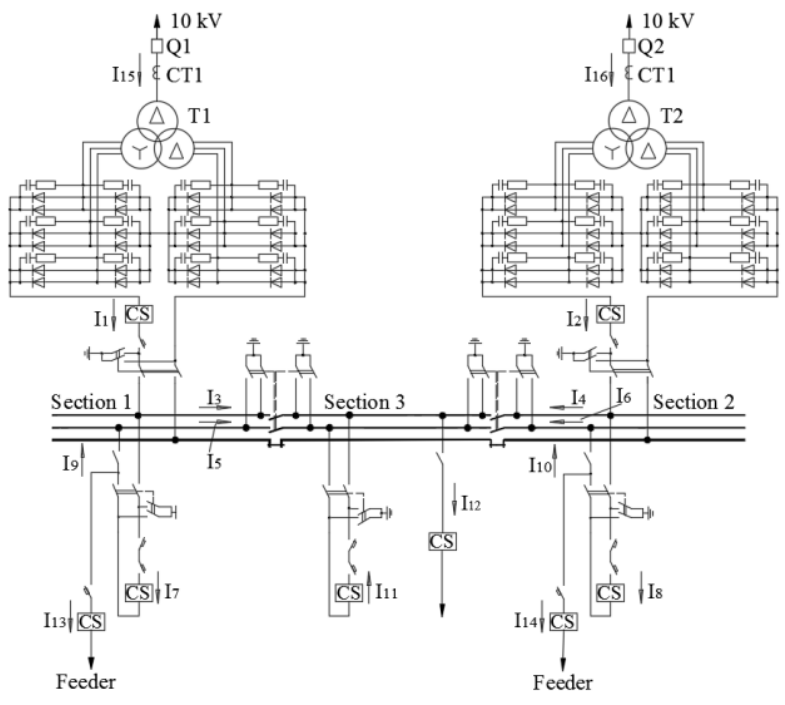

Fig. 1. Scheme of fragment of the DC traction substation.

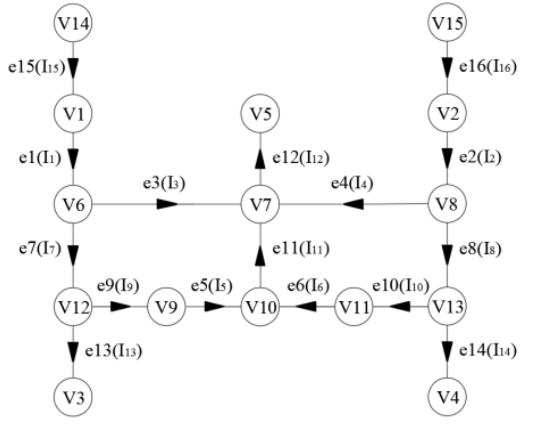

a)

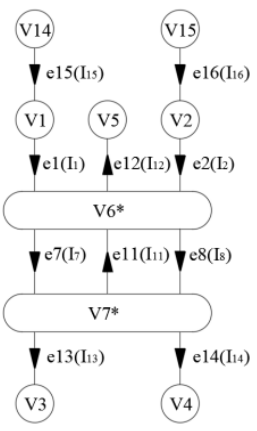

b)
Fig. 2. Unidirectional graph for the fragment of the DC traction substation. a) initial graph; b) final graph

Then it is determined whether to trigger starting on fault in the region, or there is a CT, CS or communication lines (CL) fault. The presence of a fault is determined using the method of double entry. Since

\footnotetext{
Corresponding author: anton8094@mail.ru
} 
each arc of the graph is reflected with the same weight (current value) in the matrices twice: as an arc, associated with the vertex directed to one matrix, and as the arc associated with the vertex directed from another matrix, in the case getting wrong values is the sum of incoming and outgoing currents in the two matrices becomes incorrect, but the total differential current of the whole network remains equal to zero. In case of observance of rule of detection of the fault and maintaining a sum of currents for the entire network is equal to zero, a CT, CS or CL fault is detected.

Signs of the functioning of the differential protection for different ratios of currents and the results of performing matrix operations for this scheme is shown in Table 1. Variables SMV1...SMV7, obtained as a result of matrix operations, determine the conditions for the presence of short circuit in the protection zone. The SUM variable determines the total differential current.

Table 1. Results matrix operations and signs of the functioning of the protection.

\begin{tabular}{|c|c|c|c|c|c|}
\hline \multicolumn{5}{|c|}{ The resulting value matrix operations } & \multirow[b]{2}{*}{ Signs of fault } \\
\hline $\begin{array}{c}S M V \\
1\end{array}$ & $\begin{array}{l}S M V \\
2\end{array}$ & $\begin{array}{c}S M V \\
6^{*}\end{array}$ & $\begin{array}{c}S M V \\
7 *\end{array}$ & $S U M$ & \\
\hline 0 & 0 & 0 & 0 & 0 & $\begin{array}{l}\text { Fault is missing, } \\
\text { CTs is functioning. }\end{array}$ \\
\hline 0 & 0 & $\neq 0$ & 0 & $\neq 0$ & Fault on $V 6^{*}$. \\
\hline 0 & 0 & 0 & $\neq 0$ & $\neq 0$ & Fault on $V 7^{*}$ \\
\hline 0 & 0 & $\neq 0$ & $\neq 0$ & $\neq 0$ & Fault on $e_{7}\left(e_{8}, e_{11}\right)$ \\
\hline 0 & 0 & $\neq 0$ & $\neq 0$ & 0 & $\begin{array}{l}\text { CT Fault on } e_{7}\left(e_{8} \text {, }\right. \\
\left.e_{11}\right) \text {. }\end{array}$ \\
\hline 0 & 0 & $\neq 0$ & 0 & 0 & $\begin{array}{l}\text { Fault on CS } \\
\text { common for } \\
V 6^{*}, V 1,(V 2, V 5) \\
e_{1}\left(e_{2}, e_{12}\right)\end{array}$ \\
\hline 0 & 0 & 0 & $\neq 0$ & 0 & $\begin{array}{l}\text { Fault on CS } \\
\text { common for } V 7^{*}, \\
V 3 \text {, or } V 4 e_{13}\left(e_{14}\right) \text {. }\end{array}$ \\
\hline$\neq 0$ & 0 & 0 & 0 & $\neq 0$ & Fault on $V 1$ \\
\hline 0 & $\neq 0$ & 0 & 0 & $\neq 0$ & Fault on $V 2$ \\
\hline$\neq 0$ & 0 & 0 & 0 & 0 & CT Fault on $e_{15}$ \\
\hline 0 & $\neq 0$ & 0 & 0 & 0 & CT Fault on $e_{16}$ \\
\hline 0 & 0 & 0 & 0 & $\neq 0$ & $\begin{array}{l}\text { Fault on one of CS, } \\
\text { (CT) } e_{13}, e_{14}, e_{15}, \\
e_{16}\end{array}$ \\
\hline
\end{tabular}

As a result, depending on the ratio of the currents in the scheme as well as results of operations on matrices it can implement the reliable operation of the differential protection of DC traction substation. This provides not only the action of protection in case of damage on each site, but excluded its excessive action when damaged current transformers and current sensors.

\section{Quantitative assessment of the reliability of the proposed protection}

To quantify the advantages of the proposed technical solutions from the point of view of reliability, using the method of Markov chains. This method is often used to describe the processes of failure and repair with the elementary streams, and is most suitable for calculating reliability of system of relay protection (SRP) $[5,6]$. The distribution laws of failure and repair will accept exponential.

Taking into account specificity of the analyzed differential protection, define two types of protection failures [7]: undesired-tripping protection failures (in the absence of fault on the protected object), and fail-tooperate protection failures (in case of fault on the protected object).This approach is used in several papers, e.g. [8].

In fig. 3 presents two variants of the relay protection system organization is presented. In first case (fig. 3a) the SRP, consisting of current protections (A1, A2), earth protections $(\mathrm{B} 1, \mathrm{D}), \mathrm{DC}$ current protection - $(\mathrm{C} 1)$; in the second case (fig. 3b) - a system with application CDP (F).

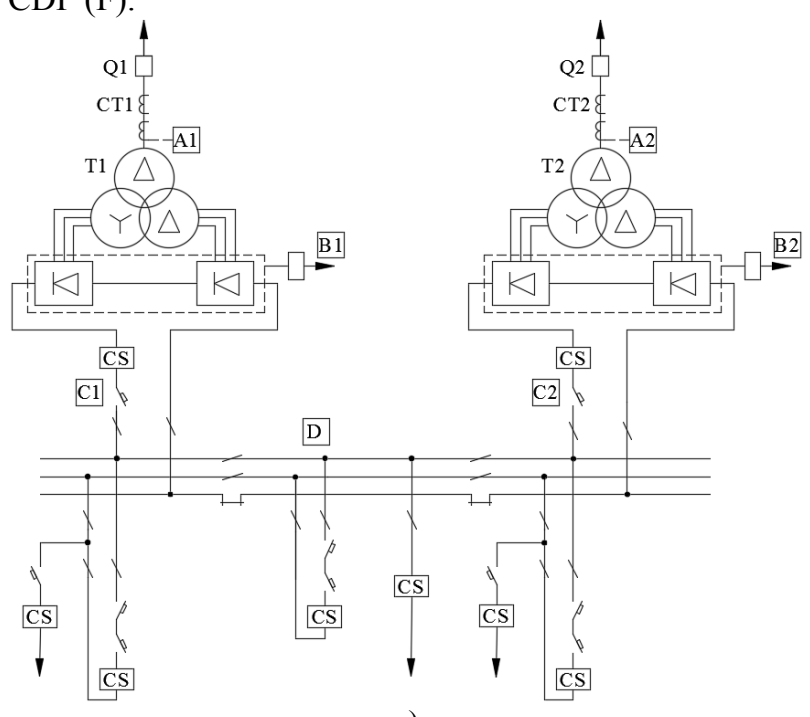

a)

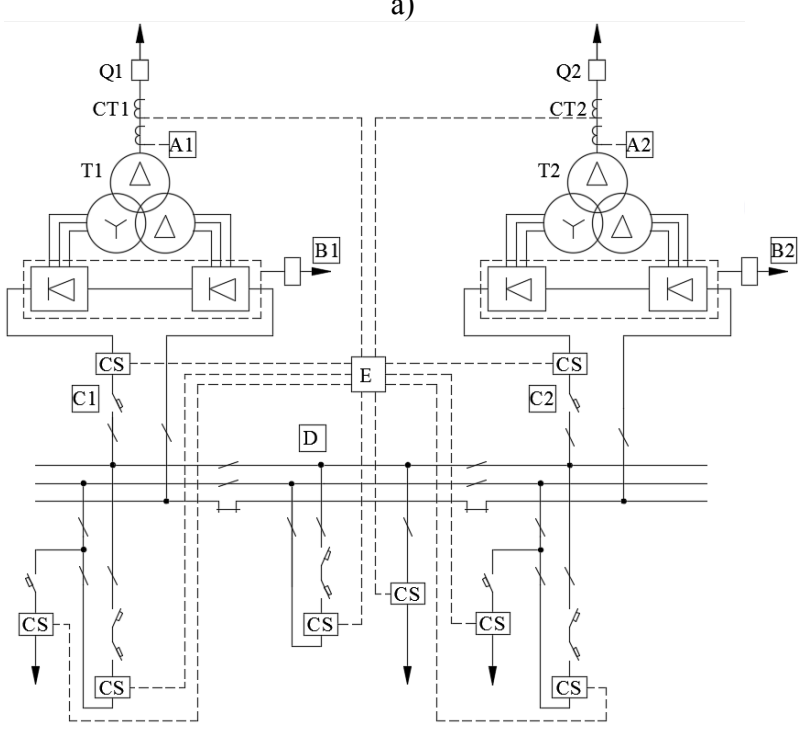

b)

Fig. 3. Protection scheme of DC traction substation with connection of protections to $\mathrm{CT}$ and $\mathrm{CS}$, a) standard protection scheme; b) system with the usage of CDP.

We will calculate reliability indexes for both cases. The initial data for calculations are obtained on the basis of $[9,10]$ and from manufacturers of protection devices. The data is presented in Table 2 . 
Table 2. Initial data for reliable indexes calculation.

\begin{tabular}{|l|c|}
\hline Parameter & Value \\
\hline Mean time between failures of protection (hour) & 100000 \\
\hline Mean restoration time of protection (hour) & 2 \\
\hline Queueing time (hour) & 2 \\
\hline Rate of false alarms of CDP (1/year) & 0,0307 \\
\hline Rate of failures to trip of CDP (1/year) & 0,0876 \\
\hline $\begin{array}{l}\text { Rate of false alarms of current protection } \\
\text { (1/year) }\end{array}$ & 0,0307 \\
\hline $\begin{array}{l}\text { Rate of failures to trip of current protection } \\
\text { (1/year) }\end{array}$ & 0,0876 \\
\hline Rate of false alarms of earth protection (1/year) & 0,00338 \\
\hline $\begin{array}{l}\text { Rate of failures to trip of earth protection } \\
\text { (1/year) }\end{array}$ & 0,00349 \\
\hline Rate of false alarms of DC protection (1/year) & 0,03 \\
\hline Rate of failures to trip of DC protection (1/year) & 0,03 \\
\hline Mean time between failures of CT (hour) & 400000 \\
\hline $\begin{array}{l}\text { Rate of CT failures including secondary circuits } \\
\text { (1/year) }\end{array}$ & 0,0429 \\
\hline Rate of busbars 3,3 kV failures (1/year) & 0,03 \\
\hline Rate of rectifier unit failures (1/year) & 0,25 \\
\hline
\end{tabular}

\subsection{Mode 1: absence of fault on the protected object}

In fig. 4 shows graphs of states and transitions in an absence of fault on the protected object mode. Here: Ew - state SRP without failures; $A 1_{1}, A 2_{1}, . . E_{1}$ - the state of the SRP in the presence of defects that could lead to undesired-tripping protection failures of devices of relay protection A, B...F, and, as a result, failure of the SRP in general; $\mu_{1}$ - repair rate of the protection, $\mathrm{CS}$ and $\mathrm{CT}$.

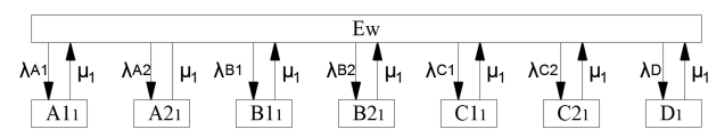

a)

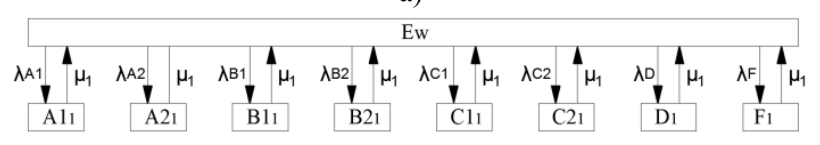

b)

Fig. 4. Graphs of states and transitions for an absence of fault on the protected object mode a) system without CDP, b) system with CDP.

Convert the graphs (fig. 4) to the form shown in fig. 5, where $E_{1}$ - failure state of SRP, $\lambda_{1}-$ the resulting failure rate of protection.

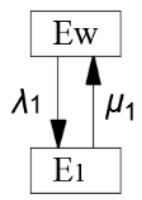

Fig. 5. Converted graph of states and transitions for an absence of fault on the protected.

Define the probability $P_{1}(t)$ that the system is in state $\mathrm{E}_{1}$, which is an emergency, for random time $t$. Form a system of differential equations describing a graph, where $P_{w}(t)$ - the probability of location the system in state without failures $\mathrm{E}_{\mathrm{w}}$.

$$
\left.\begin{array}{l}
\frac{d P_{w}(t)}{d t}=-\lambda_{1} \cdot P_{w}(t)+P_{1}(t) \cdot \mu_{1} \\
\frac{d P_{1}(t)}{d t}=\lambda_{1} \cdot P_{w}(t)-P_{1}(t) \cdot \mu_{1}
\end{array}\right\}
$$

Normalizing expression, the meaning of which is that the researched system located in state $E_{1}$ or $E_{w}$ as constituting a complete group of events, has the form

$$
P_{w}(t)+P_{1}(t)=1
$$

As at the initial moment of operation of the system at $t=0$ the system is in state without failures:

$$
P_{w}(0)=1, P_{1}(0)=0
$$

As a result of solve the system of differential equations a function of the unreadiness probability

$$
q(t)=P_{1}(t)=\frac{\lambda_{1}}{\lambda_{1}+\mu_{1}} \cdot\left(1-\exp \left[-\left(\lambda_{1}+\mu_{1}\right) t\right]\right)
$$

Make an assessment of the probability of failure-free operation of the SRP. The graph for the calculation will look similar as the graph in fig. 5 with the difference that it will not be possible to transition from state $\mathrm{E}_{1}$ to $\mathrm{Ew}$, that is excludes repair rate $\mu_{1}$. This circumstance is due to the fact that when system fails (transition to absorbing state $E_{1}$ ), the experiment is finished - the system cannot leave this state.

Due to absence of repair instead of a system of differential equations (1), the result will be an expression of the probability of failure-free operation (PFFO), with exponential distribution law:

$$
R(t)=P_{w}(t)=\exp \left[-\left(\lambda_{1} \cdot t\right)\right]
$$

In fig. 6 shown the dependences of the function of the unreadiness probability of SRP, and functions of the PFFO on the average time between checks.



a) 


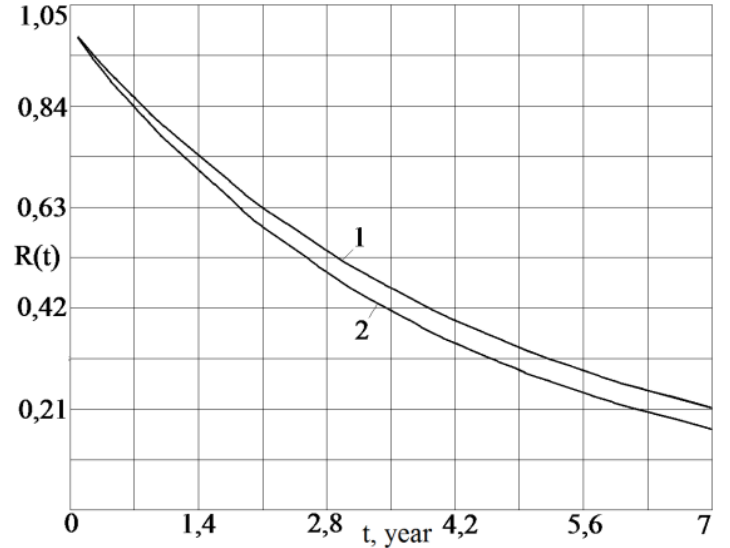

b)

Fig. 6. Function of the unreadiness of SRP (a) and function PFFO of SRP (b). 1 - system without CDP; 2 system with CDP.

\subsection{Mode 2: in case of fault on the protected object}

The calculation of reliability indicators for the damage mode on the protected object is per-formed separately for the following damages using the approach described above: short circuit in the transformer, short circuit in the rectifier, short circuit on $3.3 \mathrm{kV}$ buses.

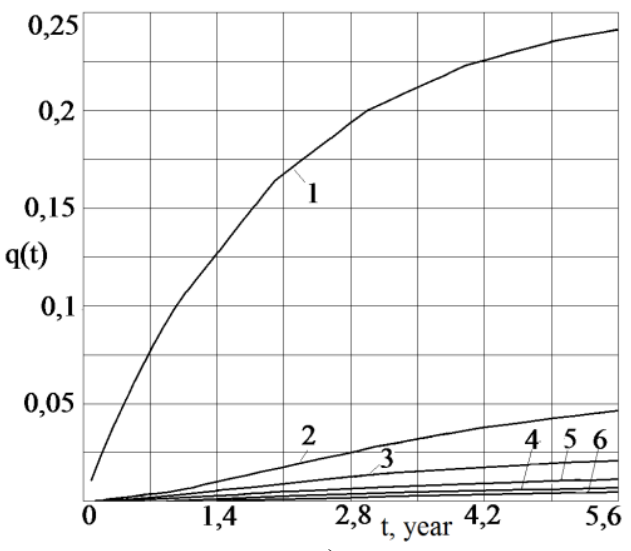

a)

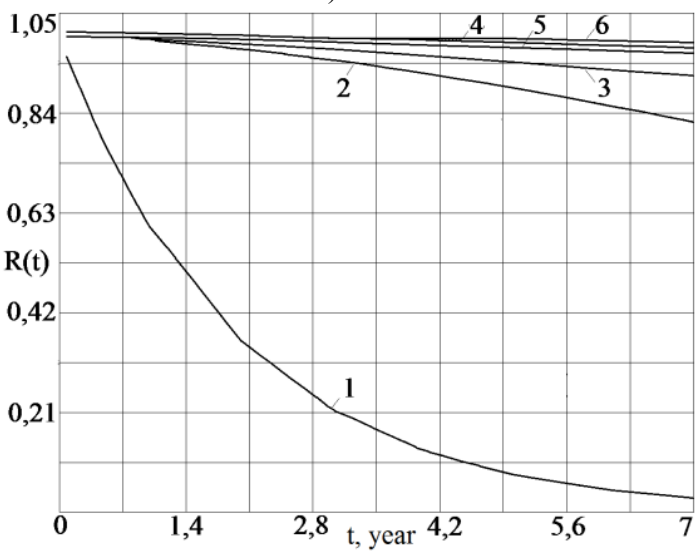

b)

Fig. 7. Function of the unreadiness of SRP (a) and function PFFO of SRP (b). 1 - standard scheme, fault in transformer; 2 CDP, fault in transformer; 3 - standard scheme, fault in rectifier; $4-\mathrm{CDP}$, fault in rectifier; 5 - standard scheme, fault on bus $3,3 \mathrm{kV} ; 6-\mathrm{CDP}$, fault on bus $3,3 \mathrm{kV}$.
Analysis of numerical calculations of indicators of reliability of the relay protection (fig. 6,7 ) shows:

- developed protection in the mode 2 has higher indicators of reliability than standard technical solution on average up to 5 times;

- the obtained calculation ratio can be used in the methods of practical reliability analysis of centralized relay protection of DC traction substation.

\section{Conclusions}

1. Proposed a new principle of organization of the centralized differential protection of DC traction substation.

2. Developed technical solutions allow to detect the current transformers, current sensors and communication channels faults, and having high reliability.

3. Protection can be adapted to changes in the configuration of the DC traction substation.

4. The proposed technical solution can increase the reliability of the differential relay protection, what follows from by the results of practical calculations.

\section{References}

1. K.G. Markvardt, Jelektrosnabzhenie jelektrificirovannyh zheleznyh dorog (Moscow,Transport, 1982)

2. V.F. Harisov, Zashhita kontaktnoj seti postojannogo toka ot korotkih zamykanij (Moscow,Transport, 1987)

3. A.L. Kulikov, V.Ju. Vukolov, A.A. Kolesnikov, Vestnik NGIEI. 2 (69), 71 (2017)

4. A.L. Kulikov, V.Ju. Vukolov, A.A. Kolesnikov, M.D Obalin, Jelektricheskie stancii. 1 (1038), 40-51 (2018)

5. B.H. Smeets, M.H.J. Bollen, Stochastic modelling of protection systems: comparison of four mathematical techniques (Eindhoven, TU/e, 1995)

6. B.V. Papkov, A.L. Kulikov, Teorija sistemy $i$ sistemnyj analiz dlja jelektrojenergetikov (Jurajt, 2016)

7. A.I. Shalin, Nadezhnost' $i$ diagnostika relejnoj zashhity jenergosistem (Novosibirsk, NGTU, 2002)

8. Je.P. Smirnov, Elektrichestvo, 9, 44 (1965)

9. A. Khurram, H. Ali, A. Tariq, O. Hasan, Proc. of int. workshop Formal Methods for Industrial Critical Systems, 169-183 (2013)

10. A.V. Efimov, A.G. Galkin Nadezhnost' i diagnostika sistem jelektrosnabzhenija zhe-leznyh dorog: Ucheb. dlja studentov vuzov zh. - d. transp. (Moscow, UMK MPS Rossii, 2000) 